\title{
B3LYP Study of 3-hydroxynaphthalene-2-carboxanilide para-derivatives
}

\author{
Martin Michalík, ${ }^{\star}$ Peter Poliak and Vladimír Lukeš \\ Department of Chemical Physics, Slovak University of Technology in Bratislava, Radlinského 9, \\ SK-812 37 Bratislava, Slovakia \\ *Corresponding author: E-mail: martin.michalik@stuba.sk
}

Received: 17-03-2017

\begin{abstract}
A systematic DFT investigation of 3-hydroxy- $N$-phenylnaphthalene-2-carboxamide and its sixteen para-derivatives is presented. The structural analysis showed that the energetically preferred conformation of all derivatives is practically planar and it is stabilised via intramolecular hydrogen bonds occurring between $(\mathrm{C}) \mathrm{O} \cdots \mathrm{H}(3) \mathrm{O}$ atomic pairs. The quantum chemically evaluated partition coefficients logarithms correlate well with Quantitative Structure-Activity Relationship models as well as with experimentally determined isocratic retention factors logarithm. Theoretical gas-phase proton affinities of amido and hydroxyl group together with selected partial atomic charges reflect the terminal phenyl substitution effect. These quantities are linearly dependent on the in vitro activity against the Mycobacterium Kansasii. Obtained linear correlation functions based on quantum chemically evaluated microscopic properties and selected experimental data may serve as the effective tool in modern drug design for the description of substitution effect.
\end{abstract}

Keywords: Descriptor of substituent effects, Hammett constants, Retention factor, Biological activity, Acidity

\section{Introduction}

In the last two decades, much effort has been paid to the development and the synthesis of new antimicrobial chemotherapeutics due to the dramatic increase of drug-resistant bacteria. ${ }^{1} \mathrm{~A}$ large number of biologically active organic compounds consists of an amide (-NH-CO-) moiety with hydrophobic residue in its close vicinity. Due to its electronic properties, the amide functional group is able to interact with a number of enzymes/receptors and affect the biological response. ${ }^{2}$ Therefore the reason for widespread occurrence of amides in pharmaceutical research is obvious. Properties of the amide group can be easily tuned by various chemical modifications. In this context, we can mention salicylanilides. ${ }^{3,4}$ These N-substituted hydroxybenzamides represent compounds with a wide range of pharmacological activities., ${ }^{5,6}$ The exact mechanism of action is still under investigation, but these compounds are known to act as inhibitors of protein kinase epidermal growth factor receptor. ${ }^{7}$ Moreover, the salicylanilides were also found to inhibit bacterial enzymes. $^{8-11}$

In the drug design and discovery the pharmacokinetic behaviour, i.e. solubility, absorption, distribution, metabolism and excretion of a compound play a crucial role. All these properties strongly depend on the lipophilicity of the compound making it one of the key parameters in the prediction and determination of pharmacological activity of potential drugs. ${ }^{12-15}$ Lipophilicity as defined by IUPAC is the affinity of a molecule or its moiety to lipophilic environment. ${ }^{16}$ Generally, it is expressed as octanol-water partition coefficient $P$, which can be determined experimentally and by computational methods. Nowadays, the chromatographic determination of lipophilicity is one of the most popular approaches due to the simple instrumentation and extensive range of measurable lipophilicity values. ${ }^{17}$ It can also be expressed by means of lipophilicity indices. The most common one is the retention factor $k$. It is obtained by the reversed phase high performance liquid chromatography (RP-HPLC) with isocratic elution. However, better correlations with $\log P$ can be reached if the retention factor $k$ is extrapolated to the mobile phase with a $0.0 \%$ concentration of the organic solvent. ${ }^{18}$ On the other hand, popular Molinspiration quantitative structure-activity relationship model (QSAR model) exists as an online partition coefficient calculator and will be denoted as miLog $P .{ }^{19}$ Based on group contributions, miLog $P$ identifies a total of 220 molecular fragments which include charge interactions. Alternatively, the $\mathrm{X} \log P 3$ values represent a knowledge-based approach 
based on additive atom/group model which starts from the known $\log P$ value of a similarly reference compound. ${ }^{20}$ Finally, the ALogPs is a self-learning method based on the use of associative neural networks to predict the $\log P$ value of a compound from its molecular structure..$^{21-23}$ Despite having certain limitations, these models are used extensively to estimate the $\log P$ values of potential drugs. ${ }^{24,25}$

Currently, the quantum chemical Density Functional Theory (DFT) method is widely used for the calculation of molecular and electronic structure. It is no surprise that the lipophilicity is tightly related to the molecular electronic structure. Moreover, the effect of various solvents and molecular conformations on the selected properties can be investigated. The DFT can be helpful for evaluation of energy related quantities, geometric parameters, as well as electromagnetic properties of molecules. ${ }^{26,27}$ Structure-activity DFT studies where the authors investigated the dependence of various biological activity descriptors on the lipophilicity and selected parameters have been published. ${ }^{28,29}$ For example, reasonable good correlation was found by studying relationships between $\log P$ and molecular properties for a larger set of polychlorinated biphenyls. ${ }^{30}$ In the case of aromatic molecules, the substitution effect is often successfully expressed by Hammett or Taft constants. ${ }^{31}$ This approach has some shortcomings. For example, the prediction of ortho substitution effect is difficult due to the specific interactions occurring between neighbouring atoms of the added group, e.g. hydrogen bond formation, steric hindrance and steric effects of bulky substituents. ${ }^{32} \mathrm{Next}$, the correlation of the local microscopic quantities, e.g. isotropic hyperfine coupling constants, nuclear magnetic resonance shifts or partial atomic charges, works very well for the atoms forming the substituted aromatic rings. Nevertheless, identification of next suitable substituent descriptors is still a challenge for theoretical chemists.

The recently published synthesis and biological activity investigations of novel ring substituted hydroxynaphthalene-2-carboxanilides and 2-hydroxynaphthalene-1caroxanilides represent a follow-up contribution to understanding the structure-activity relationship. ${ }^{3,4,9,10}$ The effect of seven substituents $\left(-\mathrm{CH}_{3},-\mathrm{F},-\mathrm{Cl},-\mathrm{Br},-\mathrm{OCH}_{3},-\mathrm{CF}_{3}\right.$ and $-\mathrm{NO}_{2}$ ) was investigated. The design of these carboxanilides was based on the principle of their ring analogy with salicylanilides. The highest lipophilicity, i.e. retention factor logarithm $(\log k)$, as well as a wide range of higher antibacterial and antimycobacterial activities was measured for 3-hydroxynaphthalene-2-carboxanilides. Especially, the well determined biological activity concentration (MIC) against Mycobacterium Kansasii was found. In vitro experiments also showed higher biological toxicity for 3-hydroxy-N-(4-nitrophenyl)naphthalene-2-carboxamide than for its ortho and meta analogues. Although the substituent effect was studied for seven substituents and the experimental data (log $k$ and $M I C)$ were correlated with electronic Hammett parameters or QSAR $\log P$ values, the modifications of electronic structure upon the ring substitution were not systematically investigated at the quantum chemical level. It is plausible to suppose that proton affinity $(P A)$, bond dissociation enthalpy $(B D E)$ and selected partial atomic charges could be promising descriptors for the quantification of substituent contributions to various experimentally relevant quantities used in drug development.

With respect to the above-mentioned facts, we decided to perform the systematic quantum chemical study of 3-hydroxynaphthalene-2-carboxamide para-derivatives (Fig. 1). Main goals of this work can be defined as follows: a) theoretical evaluation of DFT- $\log P$ values, partial atomic charges, gas-phase proton affinities of hydroxyl and amide groups for the set of 16 electron donating and electron withdrawing groups; b) correlation of these quantities with Hammett constants and available experimental data ( $\log k$ and $M I C) ; c)$ estimation of the influence of terminal phenyl substitution on the energies of frontier orbitals. Finally, the quantum chemically evaluated $\log P$ values will be compared with QSAR models.

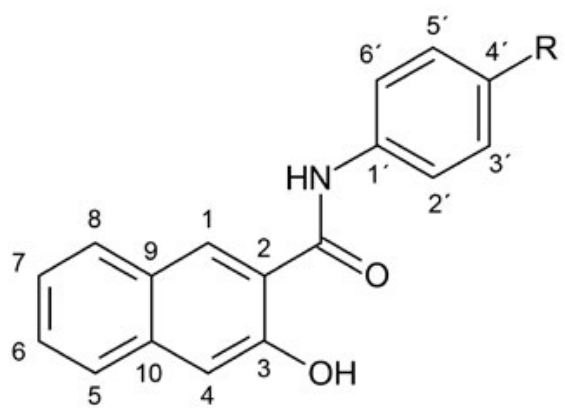

Fig. 1. Schematic structure of studied 3-hydroxynaphthalene-2-carboxamide para-derivatives with atom notation.

\section{Materials and Methods}

In order to get an accurate and precise theoretical description of the electronic and geometric properties of the molecules and of their interactions quantum chemical calculations were performed using Gaussian 09 program package. ${ }^{33}$ Optimal geometries of the studied molecules in the neutral and deprotonated forms (see Eq. 2) were calculated in the gas-phase, $n$-octanol and water by the DFT method with B3LYP (Becke's three parameter Lee-YangParr) functional without any constraints (energy cut-off of $10^{-5} \mathrm{~kJ} \mathrm{~mol}^{-1}$, final RMS energy gradient under $0.01 \mathrm{~kJ}$ $\left.\mathrm{mol}^{-1} \AA^{-1}\right) .^{34,35}$ In addition, the Grimme's dispersion corrections (GD3BJ) were included for the better description of the intramolecular interactions occurring between the added substituents. ${ }^{36}$ For all calculations, the triple-zeta 6-311++G(d,p) contracted gaussian basis sets for all atoms were employed. ${ }^{37-39}$ These basis sets can provide reliable molecular geometries and reaction enthalpies at reasonable time expense. ${ }^{40-42}$ The solvent influence was approximated by the continuum Solvation Model based on the 
quantum mechanical charge Density (SMD) of a solute molecule interacting with a continuum description of the solvent. ${ }^{43}$ The optimized structures were confirmed to be real minima by vibrational analysis (no imaginary vibrations). Then, electronic energies of frontier orbitals i.e. the highest occupied molecular orbital (HOMO) describing compounds nucleophilicity and the lowest unoccupied molecular orbital (LUMO) related to compounds electrophilicity was obtained. Partial atomic charges were evaluated using the APT (Atomic Polar Tensors) treatment. ${ }^{44}$ The theoretical partition coefficient logarithm (DFT-logP) for the water/n-octanol mixture was calculated according to Eq. 1

$$
\text { DFT }-\log P=\frac{G_{\text {water }}-G_{\text {n-cotanol }}}{2.303 R T}
$$

where $G$ values are the total Gibbs free energies of the solvated molecule, and $R$ stands for the gas constant, $R=$ $8.3145 \mathrm{~J} \mathrm{~K}^{-1} \mathrm{~mol}^{-1}{ }^{45}$ In the case of studied compounds, two possible anions can be considered. Either hydroxyl group or amide $-\mathrm{NH}$ group can be deprotonated. According to the IUPAC notation ${ }^{16}$, the gas-phase affinities of the anion were calculated by means of total enthalpies, $H$, from the Eq. 2

$$
P A=H\left(\mathrm{XN}^{-} / \mathrm{O}^{-}\right)+H\left(\mathrm{H}^{+}\right)-H(\mathrm{XNH} / \mathrm{OH})
$$

The symbol $H\left(\mathrm{XN}^{-} / \mathrm{O}^{-}\right)$stands for the total enthalpy of the formed anion, the $H\left(\mathrm{H}^{+}\right)$is the total enthalpy of the proton and $H(\mathrm{XNH} / \mathrm{OH})$ represents the total enthalpy of the investigated molecule. The gas-phase proton enthalpy $H\left(\mathrm{H}^{+}\right)=-6.197 \mathrm{~kJ} \mathrm{~mol}^{-1}$ was used, i.e. (5/2)RT. The Gibbs energies and enthalpies were determined for the room temperature $(T=298.15 \mathrm{~K})$. QSAR method tries to find descriptors holding valuable information for designing drugs with maximum biochemical activity, therefore we have used various regression models. The statistical significance of the correlations was tested by examining the correlation coefficient and the standard deviation using Origin software. ${ }^{46}$ Visualization of obtained theoretical results was done by Molekel program package. ${ }^{47}$

\section{Results and Discussion}

\section{1. Conformational Analysis}

From the geometrical point of view, the studied compounds consist of two aromatic moieties which are connected by single bonds to the $-\mathrm{NH}-\mathrm{CO}-$ bridge. The possible orientations of carbonyl atoms with respect to the hydroxyl group at the naphthyl moiety lead to four conformations. As it is presented for the parental molecule $(\mathrm{R}=\mathrm{H})$ in Fig. $1 \mathrm{~S}$, the energetically preferred conformation 1a is stabilised via the $1.708 \AA$ intramolecular hydrogen bond between (C)O and $\mathrm{H}(3) \mathrm{O}$ atoms. As it can be seen in Tab. 1S, the distance increases with the electron-withdrawing character of the substituent. The dimethylamino derivative has the shortest distance of $1.699 \AA$ while the largest value of $1.726 \AA$ is associated with the NO group. The second possible conformation 2a can be stabilised by the interaction between $\mathrm{H}(3) \mathrm{O}$ and $\mathrm{H}(\mathrm{N})$ atoms. Interestingly, this intramolecular bond length decreases with the electron-withdrawing character of the substituent. The corresponding distances for the selected derivatives are $1.853 \AA$ for the parental molecule, $1.856 \AA$ for the $-\mathrm{N}\left(\mathrm{CH}_{3}\right)_{2}$ group and $1.839 \AA$ for the $-\mathrm{NO}$ group. The calculated Gibbs free energy difference with respect to the most stable conformation of the parental molecule is of $12 \mathrm{~kJ} \mathrm{~mol}^{-1}$. According to the Boltzmann statistic, the negligible population of the second conformation at 298 $\mathrm{K}$ can be predicted. Similar results were obtained also for the substituted para-derivatives with the strong electron-donating amino group and the strong electron-withdrawing nitroxo group. Quantum chemical calculations also predicted practically planar structures of 1-hydroxynaphthalene-2-carboxanilides. The maximal distortion of 8 degrees is between the naphthyl moiety and $\mathrm{CO}$ or $\mathrm{CN}$ bonds. It seems that the presence of two aromatic moieties connected via the alternating single and double bonds ensures the impact on the whole molecular electron structure by phenyl ring substitution. The opposite arrangement of the $\mathrm{OH}$ group in conformations $\mathbf{1 a}$ and $\mathbf{2 a}$ leads to the conformations $\mathbf{1 b}$ and $\mathbf{2 b}$ where such intramolecular forces are not present. In the case of the $\mathbf{2 b}$ conformation, the strong steric repulsion between hydrogen atoms of $-\mathrm{OH}$ group and -NH- moiety (see Fig. 1S) is responsible for the significant dihedral twist. For example, the dihedral angle $\mathrm{C} 3-\mathrm{C} 2-\mathrm{C}(\mathrm{O})-\mathrm{N}(\mathrm{H})$ is about 38 degrees in all studied derivatives. Next, the mutual subtraction of the relative electronic energies $\mathbf{1 a}$ and $\mathbf{1 b}$ or $\mathbf{2 a}$ and $\mathbf{2 b}$ conformations enables us to estimate the stabilisation effect of these hydrogen bonds. For the (C) $\mathrm{O} \cdots \mathrm{H}(3) \mathrm{O}$ interaction, these energies are approximately two times larger than for the $\mathrm{H}(3) \mathrm{O} \cdots \mathrm{H}(\mathrm{N})$ one. The maximal stabilisation effect is found for the electron-donating $-\mathrm{N}\left(\mathrm{CH}_{3}\right)_{2}$ group $\left(41.6 \mathrm{~kJ} \mathrm{~mol}^{-1}\right)$. The lowest interaction energy of $35.3 \mathrm{~kJ} \mathrm{~mol}^{-1}$ exhibits the derivative containing the nitroxo group. From the energetic point of view, the intramolecular hydrogen bonds in 1a conformations are moderately strong. The reported literature data for very weak hydrogen bonds between two molecules are of $\sim 4 \mathrm{~kJ} \mathrm{~mol}^{-1}$ (e.g. $\left.\mathrm{C}-\mathrm{H} \cdots \mathrm{OH}_{2}\right)^{48}$ while the extremely strong interaction between ions $\mathrm{HF}_{2}^{-}$are stabilized with the interaction energy of $\sim 160 \mathrm{~kJ} \mathrm{~mol}^{-1}$. ${ }^{49}$

\section{2. Substituent Effect on Lipophilicity and Retention Factors}

As mentioned in the introduction, the lipophilicity parameter $\log P$ can be predicted by various QSAR models and also by means of quantum chemical calculations. For 
the unsubstituted parental molecule $(\mathrm{R}=\mathrm{H})$, the quantum chemical DFT- $\log P$ value calculated for $\mathrm{n}$-octanol/water mixture is of 2.23. The empirical models based on the octanol/water measurements give higher values, i.e. 4.48, 4.52 and 3.99 for miLog $P, X \log P 3$ and for $A \log P$ s, respectively. The data collected in Tab. 1 allow a quick comparison of substituent induced changes of the relative lipophilicity values along with the reference lipophilicity of the unsubstituted molecule. The chemical substitution, especially halogenations is able to enlarge the lipophilicity value, which is often used in the drug development. ${ }^{50}$ The maximal QSAR $\log P$ values were found for $-\mathrm{Br},-\mathrm{CH}=\mathrm{CH}_{2}$ and $-\mathrm{CF}_{3}$ groups while the amino group significantly minimizes this value. The trends obtained by the DFT approach remain the same. As illustrated in Fig. $2 S$, the quantum chemically evaluated DFT- $\log P$ values can be correlated with the QSAR ones. The best correlation was found with the Mol-Inspiration model (Tab. 2S). The correlation coefficient $R$ after omitting two strong electron donating groups $\left(-\mathrm{NH}_{2}\right.$ and $\left.-\mathrm{NMe}_{2}\right)$, one electron-withdrawing $-\mathrm{COOH}$ group and $\mathrm{CH}=\mathrm{CH}_{2}$ reached the value of 0.95. The parameters for linear function are

$$
\operatorname{miLog} P=0.491(51) \times \text { DFT }-\log P+3.54(12)
$$

Experimental retention factors $(\log k)$ for six derivatives $\left(-\mathrm{OCH}_{3},-\mathrm{CH}_{3},-\mathrm{H},-\mathrm{F},-\mathrm{Br},-\mathrm{Cl},-\mathrm{CF}_{3}\right.$ and $\left.-\mathrm{NO}_{2}\right)$ were published recently by Kos et al. ${ }^{3,4}$ These experimental values represent the logarithm of the isocratic retention factor determined by means of RP-HPLC with mobile phase containing $60 \%$ methanol and $40 \%$ water. Except for methoxy group, all substituents cause the increase of $\log k$ with the halogen substituents having the largest impact.
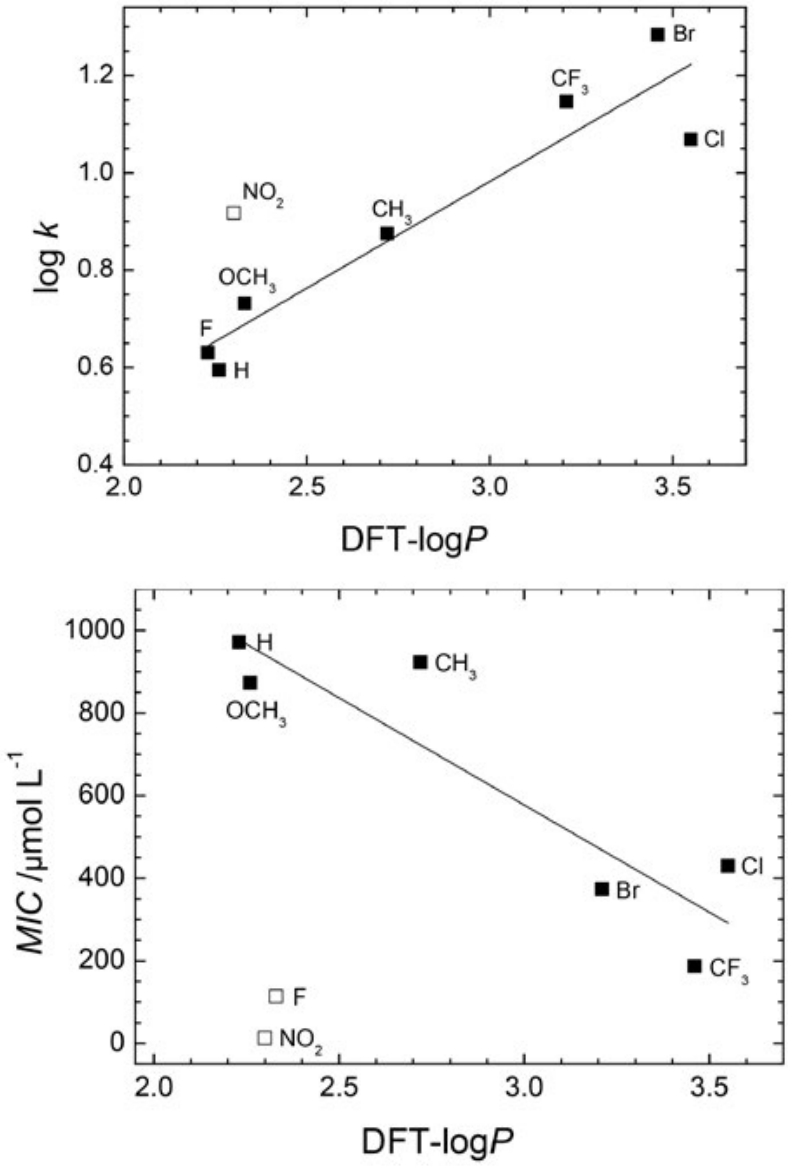

Fig. 2. Dependence of experimental retention factor logarithm $(\log k)$ and minimum inhibitory concentration (MIC) against $\mathrm{Myco}$ bacterium Kansasii on DFT-LogP. Open symbols represent the data excluded from the linear regression. DFT- $\log P$ values were calculated for the 1a conformation in water/n-octanol.

Tab. 1. Hammett constants $\sigma_{\mathrm{p}}$, DFT electric dipole moments in Debye, theoretical DFT-log $P$ values, DFT gas-phase proton affinities (PA) in kJ $\mathrm{mol}^{-1}$, the QSAR predicted $\log P$ and the experimental $\log k$ values ${ }^{3,4}$ for the studied derivatives. B3LYP results are presented for the most stable conformation la.

\begin{tabular}{|c|c|c|c|c|c|c|c|c|c|}
\hline Substituent & $\sigma_{\mathrm{p}}$ & $D$ & DFT- $\log P_{t}$ & $\mathbf{P A}(\mathrm{N}-\mathrm{H})$ & $\mathbf{P A}(\mathrm{O}-\mathrm{H})$ & $\operatorname{miLog} P$ & $\mathrm{X} \log P 3$ & $A \log P s$ & $\log k$ \\
\hline$-\mathrm{N}\left(\mathrm{CH}_{3}\right)_{2}$ & -0.83 & 5.5 & 2.95 & 1385 & 1357 & 4.58 & 4.33 & 3.75 & \\
\hline$-\mathrm{NH}_{2}$ & -0.66 & 5.2 & 2.25 & 1381 & 1352 & 3.55 & 3.52 & 3.02 & \\
\hline$-\mathrm{OH}$ & -0.37 & 5.5 & 1.02 & 1373 & 1345 & 4.00 & 4.16 & 3.46 & \\
\hline$-\mathrm{OCH}_{3}$ & -0.27 & 3.3 & 1.10 & 1374 & 1346 & 4.53 & 4.17 & 4.24 & 0.5951 \\
\hline$-\mathrm{CH}_{3}$ & -0.17 & 4.3 & 2.72 & 1373 & 1344 & 4.92 & 4.57 & 4.49 & 0.8753 \\
\hline$-\mathrm{CH}=\mathrm{CH}_{2}$ & -0.02 & 0.2 & 2.83 & 1356 & 1334 & 5.33 & 4.98 & 4.10 & \\
\hline$-\mathbf{H}$ & 0.00 & 4.0 & 2.23 & 1369 & 1341 & 4.48 & 4.52 & 3.99 & 0.6310 \\
\hline$-\mathbf{F}$ & 0.06 & 4.3 & 2.33 & 1359 & 1334 & 4.64 & 4.30 & 4.63 & 0.7317 \\
\hline$-\mathrm{SH}$ & 0.15 & 4.8 & 2.23 & 1354 & 1330 & 4.71 & 4.35 & 3.96 & \\
\hline$-\mathrm{Br}$ & 0.23 & 4.3 & 3.21 & 1349 & 1326 & 5.29 & 4.89 & 5.26 & 1.1459 \\
\hline$-\mathrm{Cl}$ & 0.23 & 4.3 & 3.55 & 1354 & 1330 & 5.15 & 4.83 & 5.19 & 1.0687 \\
\hline$-\mathrm{CHO}$ & 0.42 & 0.8 & 1.10 & 1329 & 1312 & 4.27 & 3.67 & 3.40 & \\
\hline$-\mathrm{COOH}$ & 0.45 & 5.6 & 0.74 & 1336 & 1318 & 4.39 & 3.73 & 3.87 & \\
\hline$-\mathrm{CF}_{3}$ & 0.54 & 5.2 & 3.42 & 1336 & 1315 & 5.37 & 5.09 & 4.91 & 1.2835 \\
\hline$-\mathrm{CN}$ & 0.66 & 0.3 & 1.81 & 1322 & 1306 & 4.23 & 3.92 & 3.62 & \\
\hline$-\mathrm{NO}_{2}$ & 0.78 & 7.1 & 1.48 & 1313 & 1298 & 4.43 & 4.03 & 4.18 & 0.9175 \\
\hline$-\mathrm{NO}$ & 0.91 & 6.2 & 1.91 & 1312 & 1300 & 4.37 & 3.58 & 3.53 & \\
\hline
\end{tabular}


The expected trend of increasing lipophilicity with the larger halogen atom can be observed.

After the nitro group exclusion, the data depicted in Fig. 2 show linear relationship between the $\log k$ values and DFT- $\log P$ with the correlation coefficient $R=0.94$

$$
\log k=0.438(67) \times \text { DFT- } \log P-0.33(19)
$$

In the case of the QSAR $\log P$ values, the obtained slopes with the eliminated nitro group are larger (Fig. 4S), i.e. 0.719 for $\operatorname{miLog} P, 0.76$ for $\mathrm{XLog} P 3$ and 0.90 for ALogPs. It seems that the strong electron-withdrawing $\mathrm{NO}_{2}$ group shows significantly higher experimental $\log k$ value than the evaluated dependences predict. This discrepancy is probably caused by the non-equivalent exhibition of solvent effects in model systems accounted for the $\log P$ determination in comparison with the measurements of retention factors in the solvent mixture. Additionally, the formation of dimer structures is possible ${ }^{51}$ which alters the retention factors, and therefore $\log k$.

The dependence of DFT- $\log P$ on the in vitro activity against Mycobacterium Kansasii (DSM 44162) is also noteworthy (Fig. 2). After exclusion of the data for $-\mathrm{NO}_{2}$ and -F substituents, we have obtained the linear function with $R=0.91$

$$
M I C / \mu \mathrm{mol} \mathrm{L}-1=-519(120) \times \text { DFT- } \log P+2135(354)
$$

In general, the antimycobacterial activity of potential drugs is very often affected by the differences in the permeability of the cell walls. Although all investigated compounds have the planar 1a conformation, their penetration into bacterial cells can be supported by their higher electric dipole moments together with the size of the terminal substituent. The mutual comparison of B3LYP dipole moments collected in Tab. 1 reveals that the most polar molecule is the nitro-derivative with the corresponding value of 7.1 D. For the sake of comparison, we note that the gas-phase B3LYP/6-31++G(d,p) dipole moment of non-substituted nitrobenzene of $4.9 \mathrm{D}$. This value is slightly higher comparing to the gas-phase experimental value evaluated from the dielectric constants $(4.3 \mathrm{D}) .^{52}$ On the other hand, fluorine has the highest electronegativity and may have large electronic effect on the neighbouring carbon atoms. Next, fluorine atom can act as a hydrogen bond acceptor, and its three lone pairs even enable to act as a ligand for alkali metals. Therefore, the incorporation of the fluorine atoms in a molecule will make it more lipid soluble. This means it migrates through membranes much more readily, and hence the fluorinated molecule has a higher bioavailability. ${ }^{53}$

\section{3. Substituent Effect on the Atomic Charge Distribution}

The electrostatic field in the vicinity of the molecule determines the macroscopic properties reflected in the ex- perimental retention factors or $\log k$ values. For the sake of simplicity, this electrostatic field can be approximated as the superposition of partial atomic charges. The magnitudes of these charges are consequently changed with respect to the ring substitution. In other words, the maximal and minimal values were observed for the derivatives containing the strongest electron-withdrawing nitroxo and the strongest electron-donating dimethylamino groups respectively. The mutual comparison of absolute differences obtained from the atomic partial charges $\left(Q_{\mathrm{x}}\right)$ of the above mentioned derivatives help us to determine which part of the molecule is mostly sensitive to the terminal substitution (Fig 3). The individual partial charges of non-hydrogen atoms of 3-hydroxynaphthalene-2-carboxanilide for $-\mathrm{NO}$ and $-\mathrm{N}\left(\mathrm{CH}_{3}\right)_{2}$ derivatives are available in Tab. $4 \mathrm{~S}$

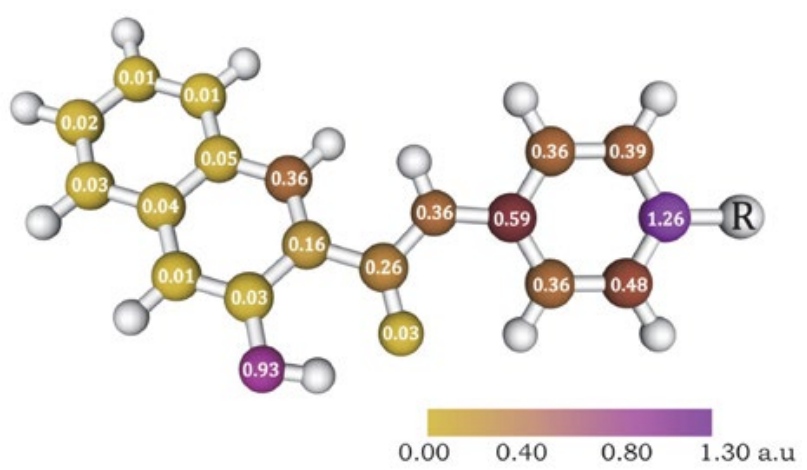

Fig. 3. Absolute differences between the B3LYP APT atomic partial charges in atomic units for non-hydrogen atoms of 3-hydroxynaphthalene-2-carboxanilide moiety of $-\mathrm{NO}$ and $-\mathrm{N}\left(\mathrm{CH}_{3}\right)_{2}$ derivatives. The calculations were performed for the $\mathbf{1 a}$ conformation.

It seems that the substituent effect expands beyond the amidic bond in the case of the $\mathrm{C} 2$ atom and the oxygen atom of the $\mathrm{OH}$ group on the naphthyl moiety. However, the negligible charge sensitivity to the substitution can be seen at other naphthyl ring atoms. The linear dependence of the atomic charge on the Hammett constants was found only for $\mathrm{C} 2, \mathrm{~N}, \mathrm{Cl}^{\prime}$ and $\mathrm{C}(=\mathrm{O})$. As shown in Fig. 4S, the positive partial charges on $\mathrm{Cl}^{\prime}$ and $\mathrm{C}(=\mathrm{O})$ atom increase as the substituent possess a more electron-accepting nature (see Tab. 1). On the other hand, the negative slopes of -0.0940 and -0.215 were observed for the Hammett type dependences for the charges on $\mathrm{C} 2$ and $\mathrm{N}$ atoms. Based on

Tab 2. Linear dependence parameters and correlation coefficients for the dependence of B3LYP APT partial charges in atomic units of selected carbon and nitrogen atoms on the Hammett constants.

\begin{tabular}{cccc}
\hline Atom & Slope & Intercept & $\boldsymbol{R}$ \\
\hline C1' & $0.352(28)$ & $0.531(14)$ & 0.956 \\
C2 & $-0.0940(51)$ & $-0.4127(25)$ & 0.979 \\
C(=O) & $0.154(11)$ & $1.4642(58)$ & 0.960 \\
N & $-0.215(22)$ & $-1.004(11)$ & 0.929 \\
\hline
\end{tabular}


the comparison of the slope values presented in Tab. 2, we can conclude that $\mathrm{C1}^{\prime}$ and $\mathrm{N}$ atoms exhibit the largest changes of partial charges upon the para-substitution.

Possible importance of the electrostatic interaction between these atoms and solvent molecules in the chromatographic retention times can be estimated from the direct correlation with the experimental $\log k$ values (Fig. 4). After the exclusion of $\log k$ value for $\mathrm{NO}_{2}$ substituent and the parental molecule, the following linear regressions with $R$ higher than 0.98 were obtained (partial charges $Q_{\mathrm{x}}$ are in atomic units)

$$
\begin{aligned}
& \log k=2.52(30) \times Q_{\mathrm{Cl}^{\prime}}-0.41(16) \\
& \log k=-4.53(0.72) \times Q_{\mathrm{N}}-3.57(71)
\end{aligned}
$$

In the case of the nitro group, relative large atomic partial charges on the substituent atoms were found (Tab. $4 \mathrm{~S})$. The charge on the nitrogen atom is positive (1.51 a.u.) and on each of the oxygen atoms is negative ( -0.75 a.u.).
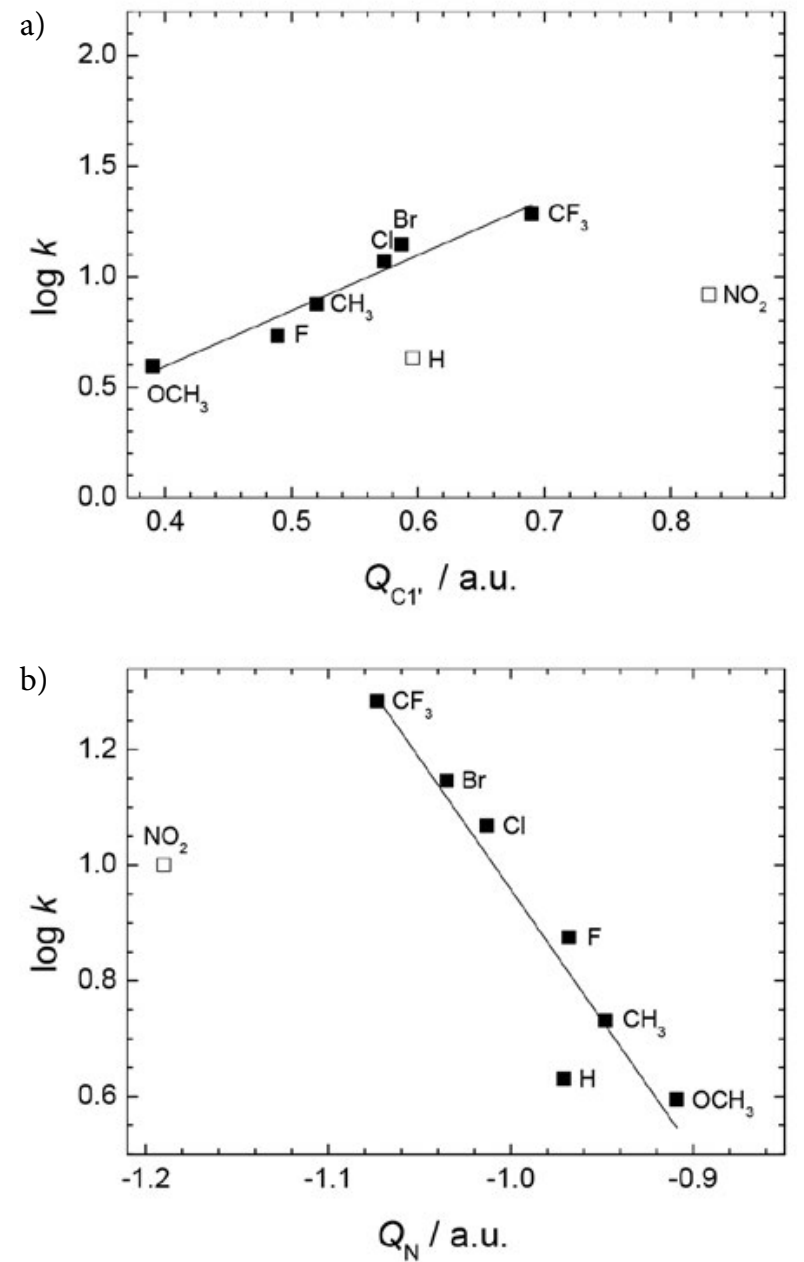

Although the relatively high positive atomic charge was also found at the carbon atom of trifluoromethyl, the orientation of fluorine atoms will ensure the electrostatic shielding effect. Therefore the found dependence could be relevant for the prediction of $\log k$ values for the derivatives with terminal substituents containing no unshielded positively charged atom connected directly to the phenyl ring.

From the next dependences illustrated in Fig. 4, it can be concluded that the linearity between the atomic partial charges on $\mathrm{Cl}^{\prime} / \mathrm{N}$ atoms and the MIC values occurs only for stronger electron-withdrawing and electron-donating groups. Correlation coefficients are better than 0.95 after omitting the parental molecule, methyl and fluoro derivatives. The linear regression equations for partial charges $Q_{X}$ in atomic units are

$$
\begin{aligned}
& M I C / \mu \mathrm{mol} \mathrm{L}^{-1}=-1964(198) \times Q_{\mathrm{C}^{\prime}}+1581(125) \\
& M I C / \mu \mathrm{mol} \mathrm{L}-1=3071(463) \times Q_{\mathrm{N}}+3582(485)
\end{aligned}
$$
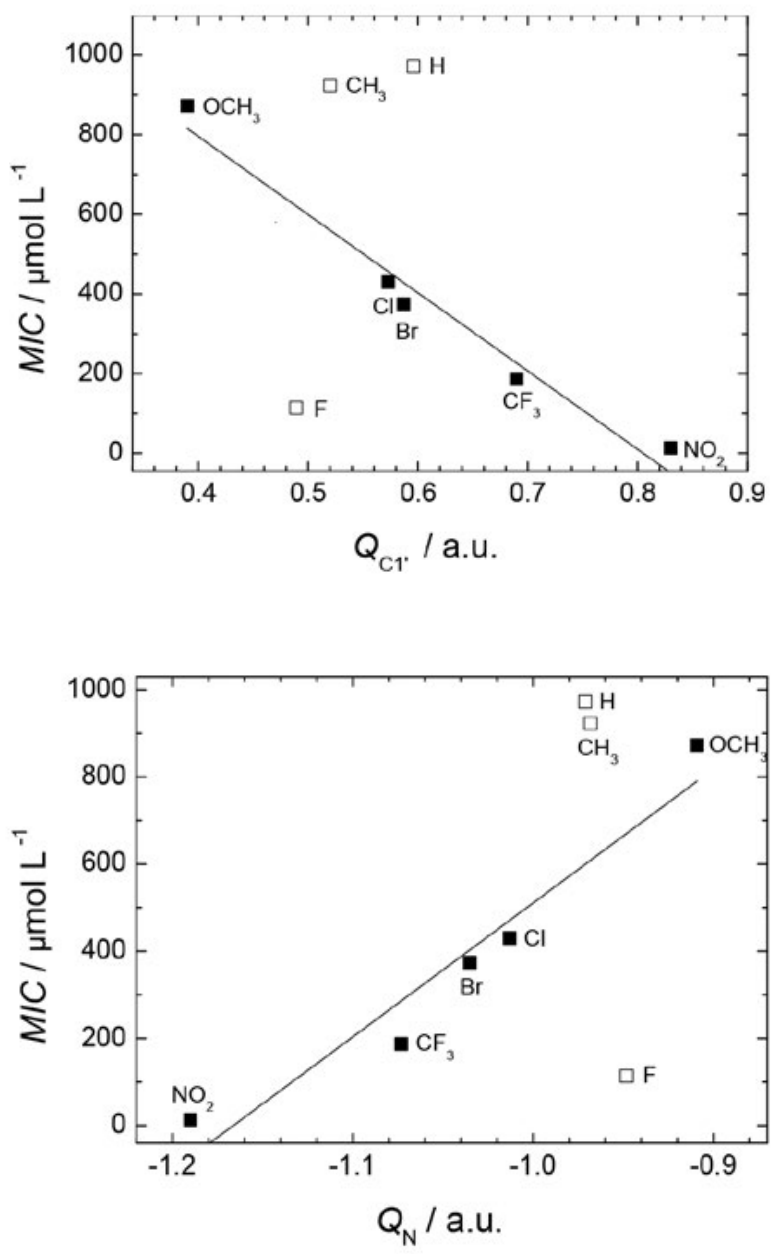

Fig 4. Dependence of the experimental retention factor logarithm (logk) and minimum inhibitory concentration (MIC) against Mycobacterium Kansasii on B3LYP APT partial charges at (a) C1' and (b) N atoms. Open symbols represent the data excluded from the linear regression. The calculations were performed for the 1a conformation. 


\section{4. Substituent Effect on the Proton Affinities of Amide and Hydroxyl Groups}

Despite the fact that the carboxanilide compounds are very weak acids, the energetics of proton abstraction could be affected by the terminal substitution. For the determination of the primary substituent effect, i.e. the influence of the electronic nature of a functional group excluding solvent and other additional effects, the gas-phase calculations of proton affinities (PA) were performed. For the energetically preferred 1a conformation, amidic group proton affinity of parental molecule is of $1369 \mathrm{~kJ} \mathrm{~mol}^{-1}$ in gas-phase. The PA for the hydroxyl group connected to the naphthyl moiety is slightly lower, i.e. $1341 \mathrm{~kJ} \mathrm{~mol}^{-1}$ (see Tab. 1). Chemical accuracy of the used calculation method can be estimated by the comparison with experimental data for well documented simple chemical structures. Experimental gas-phase PA values of phenol and aniline are of $1456 \mathrm{~kJ} \mathrm{~mol}^{-154}$ and $1541 \mathrm{~kJ} \mathrm{~mol}^{-155}$, respectively. Our calculated values are of $1441 \mathrm{~kJ} \mathrm{~mol}^{-1}$ and $1524 \mathrm{~kJ} \mathrm{~mol}^{-1}$, respectively.

The addition of a strong electron-donating group to the phenyl ring increases the PA value for amide and hydroxyl groups by about $16 \mathrm{~kJ} \mathrm{~mol}^{-1}$. On the other hand, the electron-withdrawing substitution is responsible for the almost $60 \mathrm{~kJ} \mathrm{~mol}^{-1}$ decrease of PA. From the numerical point of view, the reliability of PA value is dependent on the correctly found optimal geometry of the molecule and of its deprotonated form. In the case of these investigated carboxanilide para-derivatives in the 1a conformation, the proton abstraction from the amide group can be responsible for the strong electrostatic interaction between the hydrogen atom of the hydroxyl group and the oxygen atom of the amide group. This interaction can generate two or more energetically different conformations with respect to the hydrogen atom position of the hydroxyl group. On the other hand, the deprotonation of the hydroxyl group in the 1a conformation leads to strong repulsion between the oxygen atoms while the deprotonated anionic form can occur in various twisted conformations. Despite these complications, the linear dependences with $R=0.96$ were achieved with respect to the Hammett constants (Fig. 5S). From the linear regression, we obtained the following equations

$$
\begin{aligned}
& P A(\mathrm{O}-\mathrm{H}) / \mathrm{kJ} \cdot \mathrm{mol}^{-1}=-36.1(2.3) \times \sigma_{\mathrm{p}}+1333.2(1.1) \\
& P A(\mathrm{~N}-\mathrm{H}) / \mathrm{kJ} \cdot \mathrm{mol}^{-1}=-46.2(3.5) \times \sigma_{\mathrm{p}}+1357.2(1.7)
\end{aligned}
$$

Slope values show that the para substitution has practically equivalent influence on the proton affinities among investigated groups. It seems that the PA values could be used as the suitable descriptor of the molecular electronic structure which is responsible for the biological activity of investigated 3-hydroxynaphthalene-2-carboxanilides. As illustrated in Fig. 5, both calculated gas-phase proton affinities are linearly dependent on the in vitro activity against Mycobacterium Kansasii (DSM 44162).
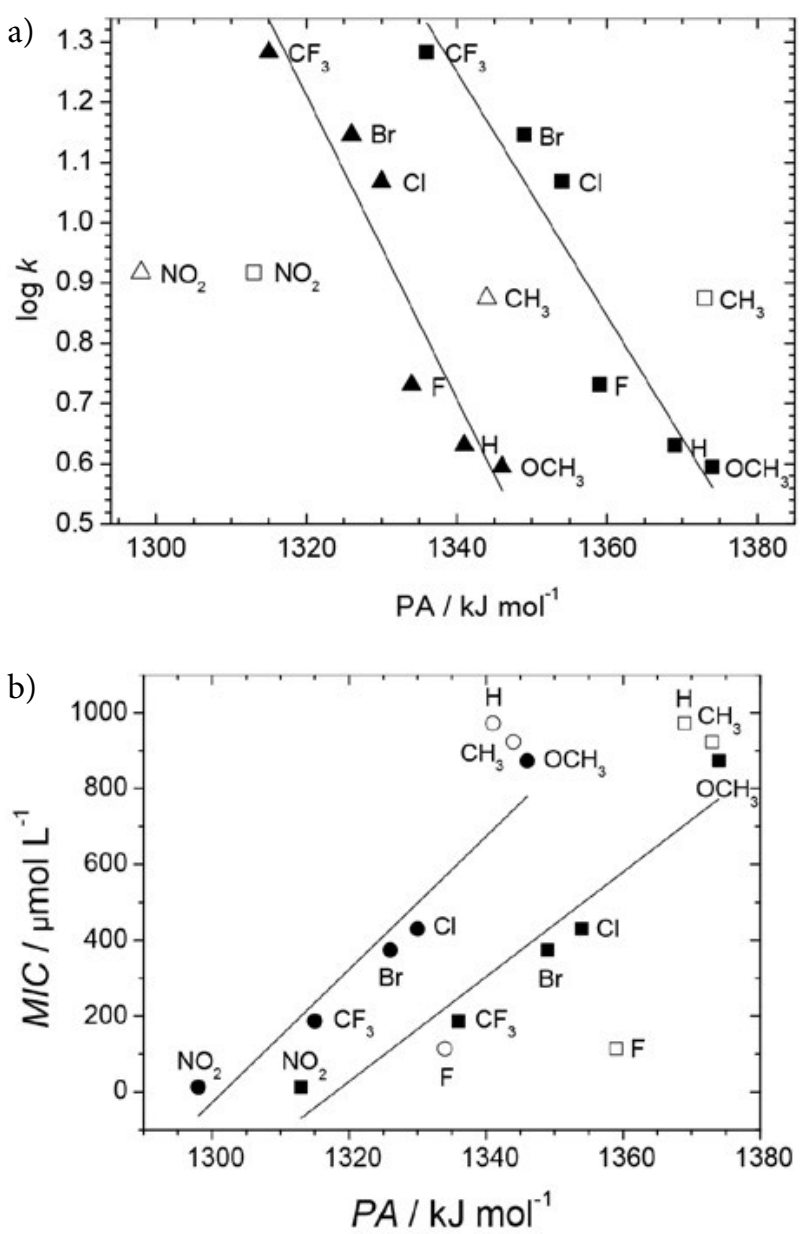

Fig. 5. Dependence of the experimental retention factor logarithm $(\log k)$ and minimum inhibitory concentration (MIC) against $\mathrm{Myco}$ bacterium Kansasii with the gas-phase B3LYP proton affinities (PA). The PAs of amide (squares) and hydroxyl (circles) groups were calculated for the 1a conformation. Open symbols stand for the data omitted from the linear regression.

The obtained correlation coefficients after exclusion of the parental molecule, methyl and fluorine derivatives are better than 0.97 . The fitted parameters for the hydroxyl group are

$M I C / \mu \mathrm{mol} \cdot \mathrm{L}^{-1}=17.5(2.5) \times P A-22800(3300)$

and for the amide group are

$M I C / \mu \mathrm{mol} \cdot \mathrm{L}^{-1}=13.8(2.1) \times P A-18200(2900)$

The PAs are in $\mathrm{kJ} \cdot \mathrm{mol}^{-1}$. From these dependencies, gas phase $P A$ turns out to be a possible descriptor of $M I C$ values and interestingly the correlation between the microscopic and macroscopic quantity is evident. The contribution of a solvent effect on the proton affinities can be also theoretically evaluated by employing B3LYP/SMD model. Nevertheless, implicit solvent model is fast and robust but still only approximation and has its own limita- 
tions. As demonstrated in Tab. 6S, calculated B3LYP/SMD proton affinities are shifted by about $1100 \mathrm{~kJ} \cdot \mathrm{mol}^{-1}$ with respect to gas phase. Correlations with experimental quantities are less linear. The obtained correlation coefficients are between 0.89-0.92.

\section{5. Substituent Effect on the Energies of Frontier Molecular Orbitals}

The terminal ring substitution should also have the influence on the redox potential. The energies of the Highest Occupied Molecular Orbital (HOMO) and Lowest Unoccupied Molecular Orbital (LUMO) as the next possible descriptors should reflect the differences in the molecular structure of the studied derivatives. As depicted in Fig. 6a, the energy of HOMO $\left(E_{\text {номо }}\right)$ correlates satisfactorily with the Hammett constants. After omitting two strong electron donating groups $\left(-\mathrm{NH}_{2}\right.$ and $\left.-\mathrm{NMe}_{2}\right)$, the correlation coefficient is of 0.96 and the parameters of the fitted dependence are

$$
E_{\text {номо }} / \mathrm{eV}=-0.282(22) \times \sigma_{\mathrm{p}}-6.0646(98)
$$

The negative slope indicates that the cation formation is supported by the electron-withdrawing substituents. Interestingly, the shapes of $\mathrm{HOMO}-1$ for $\mathrm{NH}_{2}$ and $\mathrm{NMe}_{2}$ derivatives are comparable with the HOMO shapes of the remaining species. The HOMO-1 energies for $\mathrm{NH}_{2}$ and $\mathrm{NMe}_{2}$ correlate better with the Hammett constants. As can be seen in Fig. 7S, all these molecular orbitals are delocalised over the naphthyl moiety. On the other hand, the lobes of HOMO functions for $\mathrm{NH}_{2}$ and $\mathrm{NMe}_{2}$ derivatives are delocalised over the central bridge, phenyl moiety and corresponding lone pair of the added terminal nitrogen atom. In the case of the LUMOs, two distinguished linear dependencies with respect to the Hammett constants were obtained. The parental molecule represents the border group in these dependences (Fig. 6b). For the electron-donating substituents including the parental molecule, the correlation coefficient $R=$ 0.96 . The linear function parameters based on seven points are

$$
E_{\mathrm{LUMO}} / \mathrm{eV}=-0.99(13) \times \sigma_{\mathrm{p}}-2.091(64)
$$

Significantly lower slope was obtained for the derivatives containing the electron-withdrawing substituents

$$
E_{\mathrm{LUMO}} / \mathrm{eV}=-0.277(41) \times \sigma_{\mathrm{p}}-2.191(18)
$$

The correlation coefficient evaluated from ten points, where the parental molecule was also included, is of 0.93 . Despite the presented linear dependence of HOMO/ LUMO energies on the Hammett constants, the dependence of orbital energies on the $\log k$ values depicted in Fig. $7 \mathrm{~S}$ shows no correlation. a)
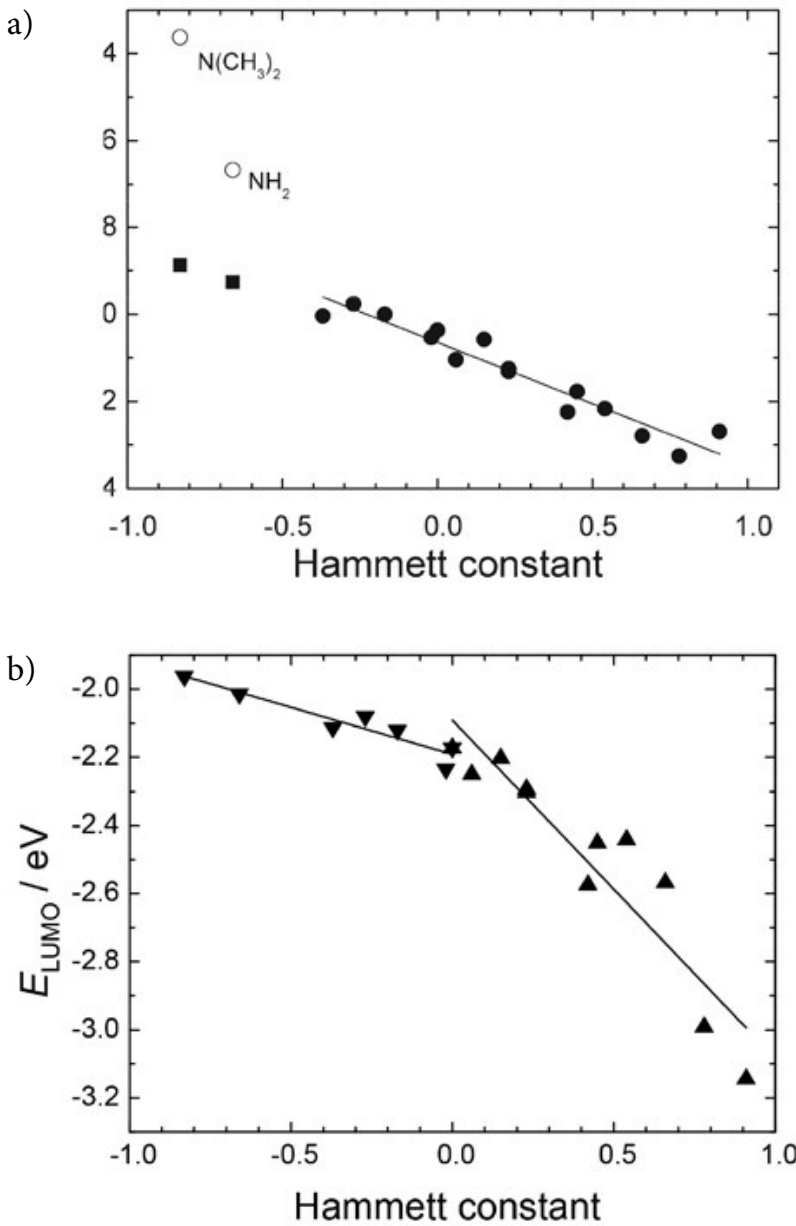

Fig. 6. Dependence of B3LYP energies of frontier orbitals HOMO (a) and LUMO (b) on the Hammett constants. Open symbols represent the data excluded from the linear regression. Squares stand for the HOMO-1 energies. The calculations were performed for the 1a conformation.

On the other hand, the HOMO energies offer linear dependence on MIC with satisfactory agreement $(R=$ 0.98 ) after rejecting outlying $\mathrm{H}, \mathrm{F}$ and $\mathrm{CH}_{3}$ derivatives

$$
\begin{aligned}
M I C / \mu \mathrm{mol} \cdot \mathrm{L}^{-1}= & 2470(250) \times E_{\mathrm{HOMO}} / \mathrm{eV}+ \\
& +15600(1500)
\end{aligned}
$$

\section{Conclusion}

The present work was focused on the systematic quantum chemical investigation of 3-hydroxy- $N$-phenylnaphthalene-2-carboxamide and its sixteen para-derivatives. The structural analysis showed that the 1a conformations are energetically preferred due to the stabilisation via the intramolecular hydrogen bonds occurring between the $(\mathrm{C}) \mathrm{O} \cdots \mathrm{H}(3) \mathrm{O}$ atomic pairs. Phenyl ring substitutions affected the whole electronic structure of the molecule as the two aromatic moieties are connected via 
the alternating single and double bonds with the practically planar arrangement corresponding to the 1a conformation. The calculations of B3LYP APT atomic charges and proton affinities confirmed indisputable impact on the - NH-CO- bridge atoms and the naphthyl moiety. Next, the substitution effect was estimated from the mutual comparison of the energies of the frontier molecular orbitals. The dependences between the $\log P$ and the charge variations at specific positions show the linear increase of the lipophilicity with the absolute value of the accumulated charge on a single atom. Based on the comparison with the experimental data obtained for the synthesized derivatives the predicted trends were confirmed. The best correlation between the quantum chemically evaluated $\log P$ values and the QSAR Molinspiration model was demonstrated. The experimental $\log k$ values were correlated with the APT charges of the amide nitrogen atom as well. Interestingly, the evaluated partial charges on $\mathrm{N}$ and $\mathrm{Cl}$ ' atoms, the gas-phase proton affinities for the dissociation of the amide and hydroxyl group of the naphthyl moiety are linearly dependent on the in vitro activity against Mycobacterium Kansasii and serve as possible descriptors. Except the parental molecule, fluorine and methyl substituted derivatives, this linearity was demonstrated only for the substituents possessing stronger electron-donating or electron-withdrawing effects. Although the energies of frontier molecular orbitals very well reflects the changes in the electronic structure upon the terminal ring substitution, only HOMO energies can be suggested as the possible descriptor for MIC quantities. Nevertheless, it should be mentioned that experimental data for a larger set of molecules could unambiguously confirm that the found dependences are relevant also for different substituents and the obtained dependences are capable to provide reliable predictions. It could be also stressed out that experimental results were correlated with the gas-phase deprotonation energetics - although the solvent does not change general trends, it usually attenuates the substituent effect. But the theoretical description of the solvent effect is not trivial. Applied implicit solvent model due to the implemented approximations may not improve the quality of predicted trends.

\section{Acknowledgments}

This work was supported by Slovak Grant Agency VEGA (project no. 1/0594/16) and Slovak Research and Development Agency under the contract No. APVV-150053. We are grateful to the HPC centre at the Slovak University of Technology in Bratislava, which is a part of the Slovak Infrastructure of High Performance Computing (SIVVP project, ITMS code 26230120002 , funded by the European region development funds, ERDF) for the computational time and resources made available.

\section{Abbreviations}

\begin{tabular}{|c|c|}
\hline APT & Atomic polar tensor \\
\hline B3LYP & $\begin{array}{l}\text { Becke three-parameter (exchange), Lee- } \\
\text { Yang-Parr (correlation) }\end{array}$ \\
\hline $\mathrm{BDE}$ & Bond dissociation enthalpy \\
\hline DFT & Density functional theory \\
\hline HOMO & Highest occupied molecular orbital \\
\hline LUMO & Lowest unoccupied molecular orbital \\
\hline MIC & Minimal Inhibitory Concentration \\
\hline $\mathrm{PA}$ & Proton affinity \\
\hline QSAR & Quantitative structure-activity relationship \\
\hline RMS & Root mean square \\
\hline RP-HPLC & $\begin{array}{l}\text { Reversed phase high performance liquid } \\
\text { chromatography }\end{array}$ \\
\hline SMD & $\begin{array}{l}\text { Solvation Model based on the quantum } \\
\text { mechanical charge Density }\end{array}$ \\
\hline
\end{tabular}

\section{Conflicts of Interest}

The authors declare that they have no conflicts of interest.

\section{References}

1. M. A. Toropova, A. M. Veselinović, J. B. Veselinović, D. B. Stojanović and A. A. Toropov, Comput. Biol. Chem. 2015, 59, 126-130. DOI:10.1016/j.compbiolchem.2015.09.009

2. M. Peško, J. Kos, K. Králová and J. Jampílek, Indian J. Chem., Sect. B: Org. Chem. Incl. Med. Chem. 2015, 54B, 1511-1517.

3. J. Kos, E. Nevin, M. Soral, I. Kushkevych, T. Gonec, P. Bobal, P. Kollar, A. Coffey, J. O’Mahony, T. Liptaj, K. Kralova and J. Jampilek, Bioorg. Med. Chem. 2015, 23, 2035-2043.

DOI:10.1016/j.bmc.2015.03.018

4. J. Kos, I. Zadrazilova, M. Pesko, S. Keltosova, J. Tengler, T. Gonec, P. Bobal, T. Kauerova, M. Oravec, P. Kollar, A. Cizek, K. Kralova and J. Jampilek, Molecules 2013, 18, 7977-7997. DOI:10.3390/molecules18077977

5. M. Kratky and J. Vinsova, Mini-Rev. Med. Chem. 2011, 11, 956-967. DOI:10.2174/138955711797068382

6. C. Dank, B. Kirchknopf, M. Mastalir, H. Kählig, S. Felsinger, A. Roller, V. Arion and H. Gstach, Molecules 2015, 20, 16861711. DOI: $10.3390 /$ molecules 20011686

7. C. Liechti, U. Sequin, G. Bold, P. Furet, T. Meyer and P. Traxler, ChemInform 2004, 35.

8. I. Kushkevych, P. Kollar, A. L. Ferreira, D. Palma, A. Duarte, M. M. Lopes, M. Bartos, K. Pauk, A. Imramovsky and J. Jampilek, J. Appl. Biomed. 2016, 14, 125-130.

DOI:10.1016/j.jab.2016.01.005

9. T. Gonec, J. Kos, I. Zadrazilova, M. Pesko, R. Govender, S. Keltosova, B. Chambel, D. Pereira, P. Kollar, A. Imramovsky, J. O’Mahony, A. Coffey, A. Cizek, K. Kralova and J. Jampilek, Molecules 2013, 18, 9397-9419.

DOI:10.3390/molecules18089397

10. T. Gonec, J. Kos, I. Zadrazilova, M. Pesko, S. Keltosova, J. Tengler, P. Bobal, P. Kollar, A. Cizek, K. Kralova and J. Jampilek, Bioorg. Med. Chem. 2013, 21, 6531-6541. 


\section{DOI:10.1016/j.bmc.2013.08.030}

11. I. Zadrazilova, S. Pospisilova, M. Masarikova, A. Imramovsky, J. M. Ferriz, J. Vinsova, A. Cizek and J. Jampilek, Eur. J. Pharm. Sci. 2015, 77, 197-207.

DOI:10.1016/j.ejps.2015.06.009

12. P. Duchowicz, E. A. Castro, Acta Chim. Slov. 2000, 47, 281292.

13. C. W. Fong, Comput. Biol. Chem. 2015, 58, 40-54.

DOI:10.1016/j.compbiolchem.2015.05.002

14. A. Guillot, Y. Henchoz, C. Moccand, D. Guillarme, J.-L. Veuthey, P.-A. Carrupt and S. Martel, Chem. Biodiversity 2009, 6, 1828-1836. DOI:10.1002/cbdv.200900115

15. Ł. Komsta, R. Skibiński, A. Berecka, A. Gumieniczek, B. Radkiewicz and M. Radoń, J. Pharm. Biomed. Anal. 2010, 53, 911-918. DOI:10.1016/j.jpba.2010.06.024

16. A. Wilkinson and A. McNaught, IUPAC Compendium of Chemical Terminology (the "Gold Book"), Blackwell Science, Oxford, 1997.

17. C. Liang and H.-z. Lian, TrAC, Trends Anal. Chem. 2015, 68, 28-36. DOI:10.1016/j.trac.2015.02.009

18. M. H. Abraham, H. S. Chadha and A. J. Leo, J. Chromatogr. A 1994, 685, 203-211. DOI:10.1016/0021-9673(94)00686-5

19. Molinspiration Cheminformatics 2010, http://www.molinspiration.com/services/, accessed 20.09.2016.

20. R. Wang, Y. Fu and L. Lai, J. Chem. Inf. Model. 1997, 37, 615621.

21. R. Estrada-Tejedor, N. Sabaté, F. Broto and S. Nonell, Afinidad 2013, 70, 250-256.

22. T. Cheng, Y. Zhao, X. Li, F. Lin, Y. Xu, X. Zhang, Y. Li, R. Wang and L. Lai, J. Chem. Inf. Model. 2007, 47, 2140-2148.

DOI:10.1021/ci700257y

23. I. V. Tetko and G. I. Poda, J. Med. Chem. 2004, 47, 5601-5604. DOI:10.1021/jm0495091

24. M. Remko, A. Remková and R. Broer, Molecules 2016, 21, 185. DOI:10.3390/molecules21020185

25. M. Remko, A. Remková and R. Broer, Int. J. Mol. Sci. 2016, 17, 388. DOI:10.3390/ijms17030388

26. S. Y. Liao, J. C. Chen, L. Qian, Y. Shen and K. C. Zheng, Eur. J. Med. Chem. 2008, 43, 2159-2170.

DOI:10.1016/j.ejmech.2007.10.033

27. D. Mikulski, R. Górniak and M. Molski, Eur. J. Med. Chem. 2010, 45, 1015-1027. DOI:10.1016/j.ejmech.2009.11.044

28. K. Singhal, V. K. Sahu, P. Singh and P. Raj, Med. Chem. Res. 2013, 23, 1758-1767. DOI:10.1007/s00044-013-0752-8

29. M. Genc, Z. K. Genc, S. Tekin, S. Sandal, M. Sirajuddin, T. B. Hadda, M. Sekerci, Acta Chim. Slov. 2016, 63, 726-737.

DOI:10.17344/acsi.2016.2428

30. J. Padmanabhan, R. Parthasarathi, V. Subramanian and P. K. Chattaraj, Bioorg. Med. Chem. 2006, 14, 1021-1028.

DOI:10.1016/j.bmc.2005.09.017

31. C. Hansch, A. Leo and R. W. Taft, Chem. Rev. 1991, 91, 165195. DOI: $10.1021 / \mathrm{cr} 00002 \mathrm{a} 004$

32. M. Charton, J. Am. Chem. Soc. 1969, 91, 615-618. DOI:10.1021/ja01031a016

33. M. J. Frisch, G. W. Trucks, H. B. Schlegel, G. E. Scuseria, M. A. Robb, J. R. Cheeseman, G. Scalmani, V. Barone, B. Mennucci,
G. A. Petersson, H. Nakatsuji, M. Caricato, X. Li, H. P. Hratchian, A. F. Izmaylov, J. Bloino, G. Zheng, J. L. Sonnenberg, M. Hada, M. Ehara, K. Toyota, R. Fukuda, J. Hasegawa, M. Ishida, T. Nakajima, Y. Honda, O. Kitao, H. Nakai, T. Vreven, J. A. Montgomery, J. E. Peralta, F. Ogliaro, M. Bearpark, J. J. Heyd, E. Brothers, K. N. Kudin, V. N. Staroverov, R. Kobayashi, J. Normand, K. Raghavachari, A. Rendell, J. C. Burant, S. S. Iyengar, J. Tomasi, M. Cossi, N. Rega, J. M. Millam, M. Klene, J. E. Knox, J. B. Cross, V. Bakken, C. Adamo, J. Jaramillo, R. Gomperts, R. E. Stratmann, O. Yazyev, A. J. Austin, R. Cammi, C. Pomelli, J. W. Ochterski, R. L. Martin, K. Morokuma, V. G. Zakrzewski, G. A. Voth, P. Salvador, J. J. Dannenberg, S. Dapprich, A. D. Daniels, Ö. Farkas, J. B. Foresman, J. V. Ortiz, J. Cioslowski and D. J. Fox, Gaussian Inc. Wallingford, CT 2009.

34. C. Lee, W. Yang and R. G. Parr, Phys. Rev. B 1988, 37, 785-789. DOI:10.1103/PhysRevB.37.785

35. A. D. Becke, Phys. Rev. A 1988, 38, 3098-3100. DOI:10.1103/PhysRevA.38.3098

36. S. Grimme, S. Ehrlich and L. Goerigk, J. Comput. Chem. 2011, 32, 1456-1465. DOI:10.1002/jcc.21759

37. P. C. Hariharan and J. A. Pople, Theor. Chim. Acta 1973, 28, 213-222. DOI:10.1007/BF00533485

38. A. D. McLean and G. S. Chandler, J. Chem. Phys 1980, 72, 5639-5648. DOI:10.1063/1.438980

39. M. M. Francl, J. Chem. Phys 1982, 77, 3654.

DOI:10.1063/1.444267

40. E. Klein, V. Lukeš and M. Ilčin, Chem. Phys. 2007, 336, 51-57. DOI:10.1016/j.chemphys.2007.05.007

41. E. Klein and V. Lukeš, J. Phys. Chem. A 2006, 110, 1231212320. DOI:10.1021/jp063468i

42. M. Michalík, A. Vagánek and P. Poliak, Acta Chimica Slovaca 2014, 7, 123-128.

43. A. V. Marenich, C. J. Cramer and D. G. Truhlar, J. Phys. Chem. B 2009, 113, 6378-6396. DOI:10.1021/jp810292n

44. J. Cioslowski, J. Am. Chem. Soc. 1989, 111, 8333-8336. DOI:10.1021/ja00204a001

45. P. W. Atkins, Physical Chemistry, $6^{\text {th }}$ ed., Oxford University Press, 1999.

46. Origin. ver. 8.5, OriginLab, Northampton, MA, USA

47. U. Varetto MOLEKEL Version 5.4 2009, Swiss National Supercomputing Centre: Manno.

48. L. Qingzhong, N. Wang and Y. Zhiwu, J. Mol. Struct.: THEOCHEM 2007, 847, 68-74.

DOI:10.1016/j.theochem.2007.08.035

49. J. W. Larson and T. B. McMahon, Inorg. Chem. 1984, 23, 2029-2033. DOI:10.1021/ic00182a010

50. C. L. Gentry, R. D. Egleton, T. Gillespie, T. J. Abbruscato, H. B. Bechowski, V. J. Hruby and T. P. Davis, Peptides 1999, 20, 1229-1238. DOI:10.1016/S0196-9781(99)00127-8

51. S. Tsuzuki, K. Honda, T. Uchimaru and M. Mikami, J. Chem. Phys. 2006, 125, 124304. DOI:10.1063/1.2354495

52. T. G. Scholte, Recl. Trav. Chim. Pays-Bas 2010, 70, 50-56. DOI:10.1002/recl.19510700109

53. M. V. B. Krishna, S. V. Rao, V. S. N. Murthy and D. Karunasagar, Anal. Methods 2012, 4, 1565.

DOI:10.1039/c2ay05718b 
54. L. A. Angel and K. M. Ervin, J. Phys. Chem. A 2006, 110, 10392-10403.

DOI:10.1021/jp0627426
55. S. W. Wren, K. M. Vogelhuber, T. Ichino, J. F. Stanton and W. C. Lineberger, J. Phys. Chem. A 2012, 116, 3118-3123. DOI:10.1021/jp211463r

\section{Povzetek}

$S$ teorijo gostonega funkcionala (DFT) smo sistematično raziskali 3-hidroksi- $N$-fenilnafthalen-2-carboksiamid in njegovih šestnajst para-derivativov. Strukturna analiza je pokazala, da je energetsko ugodnejša konformacija vseh derivatov praktično planarna in stabilizirana preko intramolekularnih vodikovih vezi med $(\mathrm{C}) \mathrm{O} \cdots \mathrm{H}(3) \mathrm{O}$ atomskimi pari. Vrednosti logaritmov porazdelitvenih koeficientov, dobljenih s kvantno kemijskimi računi, so v dobri korelaciji tako $s$ kvantitativnimi strukturnimi razmerji kot tudi z eksperimentalno določenimi logaritmi izokratskih retenzijskih faktorjev. Teoretične protonske afinitete amido in hidroksilne skupine v plinski fazi skupaj z izbranimi delnimi atomskimi naboji odražajo terminalni substitucijski učinek fenila in so linearno odvisne od aktivnosti in vitro proti Mycobacterium Kansasii. Dobljene linearne korelacijske funkcije, ki temeljijo na kvantno kemijsko ovrednotenih mikroskopskih lastnostih in izbranih eksperimentalnih podatkih, lahko služijo kot učinkovito orodje pri načrtovanju zdravilnih učinkovin. 